\title{
Factors associated with intimate partner violence against women in a mega city of South-Asia: multi-centre cross-sectional study
}

\author{
Niloufer S Ali, Farzana N Ali, Ali K Khuwaja, Kashmira Nanji *
}

\section{A B S T R A C T}

Objectives: To assess the proportion of women subjected to intimate partner violence and the associated factors, and to identify the attitudes of women towards the use of violence by their husbands.

Design: Cross-sectional study.

Setting: Family practice clinics at a teaching hospital in Karachi, Pakistan.

Participants: A total of 520 women aged between 16 and 60 years were consecutively approached to participate in the study and interviewed by trained data collectors. Overall, 401 completed questionnaires were available for analysis. Multivariate logistic regression analysis was used to identify the association of various factors of interest.

Results: In all, 35\% of the women reported being physically abused by their husbands in the last 12 months. Multivariate analysis showed that experiences of violence were independently associated with women's illiteracy (adjusted odds ratio $=5.9 ; 95 \%$ confidence interval, 1.8-19.6), husbands $(3.3 ; 1.9-5.8)$, and substance use $(3.1 ; 1.7-$ 5.7).

Conclusion: It is imperative that intimate partner violence be considered a major public health concern. It can be prevented through comprehensive, multifaceted, and integrated approaches. The role of education is greatly emphasised in changing the perspectives of individuals and societies against intimate partner violence.

Hong Kong Med J 2014;20:297-303

DOI: $10.12809 / \mathrm{hkmj} 134074$
NS Ali, MB, BS, FCPS
${ }^{2} \mathrm{FN}$ Ali, MB, BS
${ }^{3}$ AK Khuwaja, MB, BS, FCPS
${ }^{1} \mathrm{~K}$ Nanji *, MSc, BSCN

\begin{abstract}
Department of Family Medicine, The Aga Khan University, Karachi 74800, Pakistan

Department of Family Medicine and Community Health, University Hospitals Case Medical Center, Ohio 44106, United States

${ }_{3}$ Departments of Family Medicine/Community Health Sciences, The Aga Khan University, Karachi 74800, Pakistan
\end{abstract} husband's illiteracy $(3.9 ; 1.4-10.7)$, smoking habit of * Corresponding author: kashmira.nanji@aku.edu

New knowledge added by this study

- This study shows that women's literacy can play an important role in changing the perspectives of individuals and societies towards violence against women.

- Substance abuse including smoking and alcohol consumption may directly be responsible for intimate partner violence against women in Pakistan.

Implications for clinical practice or policy

- The growing understanding of the impact of violence needs to be translated into primary, secondary, and tertiary level prevention, including both services that respond to the needs of women living with or who have experienced violence, and interventions to prevent violence.

- There is a need for intervention programmes in all societies and cultures for both men and women to highlight this imperative issue.

\section{Introduction}

Intimate partner violence (IPV) against women is a global human rights and public health problem. Addressing violence against women (VAW) is central to the achievement of Millennium Development Goal (MDG) 3 on women's empowerment and gender equality, as well as MDGs 4,5 , and $6 .^{1}$ Intimate partner violence is defined as "the range of sexually, psychologically and physically coercive acts used against adult and adolescent women by current or former male intimate partners".
The two terms, VAW and IPV, are used interchangeably with gender-based violence. It is reported that violence imposed by husbands is the most common form of VAW. ${ }^{3}$ Data from the World Bank suggest that women aged 15 to 44 years are at greater risk from rape and domestic violence than from cancer, motor accidents, war, and malaria. ${ }^{3}$ There is enormous body of evidence to suggest that such acts of violence adversely affect the overall wellbeing of women and are associated with psychiatric morbidities like anxiety, depression, 


\section{東南亞一個大型城市中針對婦女的親密伴侶暴力 的相關因素：多中心橫斷面研究}

Niloufer S Ali, Farzana N Ali, Ali K Khuwaja, Kashmira Nanji

目的：評估婦女遭受親密伴侶暴力及相關因素的比例, 並探討婦女對 被丈夫使用暴力的態度。

設計：橫斷面研究。

安排：巴基斯坦卡拉奇一所教學醫院中的家庭醫學診所。

參與者：共520名 16 至60歲的婦女參與研究。願意參與的婦女均由受 過訓練的人員訪問。共有 401 份問卷可供分析。使用多元邏輯回歸分 析找出各種利益因素的關係。

結果： $35 \%$ 受訪者指出曾在過去 12 個月內被她們的丈夫身體虐待。 多因素分析顯示遭受暴力的經歷與以下因素有獨立的關係：文盲的 婦女（調整後的比值比 $=5.9 ； 95 \%$ 可信區間，1.8-19.6）、文盲的丈 夫（3.9；1.4-10.7）、丈夫的吸煙習慣（3.3；1.9-5.8）和藥物濫用 ( $3.1 ; 1.7-5.7$ )

結論: 親密伴侶暴力是一個重要的公共衛生問題, 可以通過完備、多 方面和綜合方法來預防。教育可顯著改變個人和社會對親密伴侶暴力 的觀點。 visiting the family practitioners in Toronto, Canada, admitted being victims of IPV. ${ }^{12}$ Another study from a developing country reported the prevalence of male partner-perpetrated violence to be around 7\%. ${ }^{13}$ Although a true comparison is difficult to make due to methodological differences between studies, in general, a higher burden of the problem is observed in developing countries, including those from South Asia. Around one third to one half of the female participants in different studies from India accept IPV victimisation. ${ }^{13,14}$ According to the recent Bangladesh Demographic Health Survey, almost half of married Bangladeshi mothers (42.4\%) with children aged 5 years and younger experienced IPV from their husbands. ${ }^{14}$ Similarly, in Pakistan, nearly one third to one half of the women stated that they are victims of IPV..$^{15,16}$

Although the prevalence of IPV varies across countries, the factors associated with an increased risk of IPV are similar. These may include substance/ alcohol use, young age, and attitudes supportive of wife beating. However, higher education status, high socio-economic status, and formal marriage offer protection against IPV. ${ }^{11,17,18}$

Limited data are available from Pakistan on VAW. The topic remains largely inadequately studied despite its far-reaching adverse consequences. Moreover, most of the published studies have been conducted in the same communities or in communities with similar socio-economic backgrounds, skewing the approximate magnitude of the problem to extremes and hampering the analysis of important demographic factors that may be associated with IPV against women. The aim of this study was therefore to estimate the proportion of women subjected to IPV in Pakistan and to examine whether demographic factors such as education status of both wife and husband and husband's involvement in substance abuse were associated with IPV. We conducted this study among women from diverse socio-economic backgrounds to assess the proportion of women subjected to IPV and the associated factors. We also aimed to determine the attitudes of participants towards the use of violence by husbands.

\section{Methods}

This cross-sectional study was conducted in four family practice clinics situated in various localities of Karachi, the largest city and economic hub of Pakistan. Karachi is one of the largest metropolitan cities of the world where over 16 million people reside; it is also called mini-Pakistan as its residents represent all the ethnicities, provinces/states, and socio-economic classes. All these clinics are affiliated with a private tertiary care teaching hospital. A total of eight family practice clinics are associated with the teaching hospital and these clinics were included as 
they provide health services to people from different socio-economic strata (lower, middle, and upper). All participants were assured of complete confidentiality of the information collected. After obtaining consent to participate in the study, currently married women (aged 16-60 years) were interviewed consecutively by four female medical students (each in a clinic) who had received prior training for this task. The data were collected simultaneously in all the clinics from July 2012 to November 2012. Sample size was calculated with the help of WHO software for sample size determination. As the prevalence of VAW ranges between $30 \%$ and $50 \%,{ }^{14-16}$ we used a prevalence of $50 \%$ for maximum variance with an error bound of $5 \%$; this gave a sample size of 385 . The sample size was then inflated by $7 \%$ for non-respondents to give a final sample size of approximately 412 .

After extensive literature search and consensus by study investigators, a structured questionnaire was developed and pre-tested. The questionnaire was initially prepared in English, translated into Urdu and then back-translated into English. The final questionnaire was comprised of sections including socio-demographic characteristics and questions regarding the experience of physical/verbal abuse inflicted ever (lifetime) by husband. In this study, physical abuse was defined by any of the following acts used against women: slapping or throwing something at her that could hurt her; pushing or shoving; hitting with fist or something else that could hurt; kicking, dragging, or beating; choking or burning on purpose; and threatening to use or actually use a gun, knife, or weapon against her. The questionnaire also included a section on the women's attitude towards use of violence by husbands against wives. Questions were also included about other variables of interest which included education status of the woman and her husband, working status of the woman and her husband, years since marriage and total number of children, family system in which the woman lives, and information about smoking status and other addictive substances used by the husband. The time required to complete the questionnaire was about 25 to 30 minutes. Due to the sensitivity of the issue, the interviews were conducted with each participant in separate rooms ensuring full privacy. The study was approved by the Research Committee of the Department of Family Medicine, Aga Khan University, Karachi, Pakistan, and prior permission was sought by administration of study clinics.

Data were analysed using the Statistical Package for the Social Sciences (Windows version 19; SPSS Inc, Chicago [IL], US). The proportion of violence experienced by women and other variables of interest were calculated. Cross-tabulation and Chi squared test were used to assess the association between the women's perception and their level of education. The independent association of factors studied with violence experienced by women was examined by multivariate stepwise logistic regression analysis to obtain odds ratios (ORs) and 95\% confidence intervals (CIs). Covariates such as education status of participants, education status of husband, and smoking and substance abuse by husband were included in the multivariate model.

\section{Results}

A total of 550 women were approached, of which 520 fulfilled the eligibility criteria. As there were 119 women who refused to participate or provided incomplete information in the questionnaire, the response rate was $77 \%$. Finally, information from 401 participants was included in the final analysis; for missing data, we averaged estimates of the variables to give a single mean estimate. The sociodemographic characteristics of the participants are summarised in Table 1. Overall, 190 (47.4\%) of the participants were aged 40 years and above, $165(41.1 \%)$ had received no education at all, and husbands of 111 (27.7\%) participants had received no schooling. A majority $(\mathrm{n}=363 ; 90.5 \%)$ of respondents were housewives while one third of the participants' husbands were not working (jobless or retired from work). Overall, 170 (42.4\%) participants had been married for more than 20 years, 265 (66.1\%) had three or more children, and $252(62.8 \%)$ were living in nuclear (single) families. Husbands of 132 (32.9\%) participants were current tobacco smokers and over one fifth of them consumed addictive substances other than tobacco smoking.

Overall, 140 (35\%) participants reported being ever physically/verbally violated by their husbands in the last 12 months. The factors associated with IPV against women on univariate analysis are summarised in Table 1. These included illiteracy of women, living in a nuclear family, and being married for more than 20 years; factors related to the husband were illiteracy, unemployment, smoking, and use of other substances besides tobacco.

In the multivariate analysis (Table 2), four factors were independently associated with IPV against women. These were women's illiteracy, husband's illiteracy, smoking habit of husband, and use of substances other than tobacco by husband. Women who were illiterate were 6 times more likely to have been violated by their husbands versus those who were literate (adjusted OR $[\mathrm{AOR}]=5.9$; 95\% CI, 1.8-19.6), while women whose husbands were illiterate were 4 times more likely to have been abused than those whose husbands were literate (AOR $=3.9 ; 95 \% \mathrm{CI}, 1.4-10.7)$. Study participants whose husbands smoked tobacco reported being victims of violence by their husbands 3 times more often than their counterparts $(\mathrm{AOR}=3.3$; $95 \% \mathrm{CI}$, 1.9-5.8). Almost similar odds for IPV were observed 
TABLE I. Distribution of socio-demographic characteristics in participants and the association of these characteristics with reported violence by their husbands $(n=40 \mathrm{I})$

\begin{tabular}{|c|c|c|c|}
\hline Socio-demographic characteristic & $\begin{array}{c}\text { No. }(\%) \text { of } \\
\text { participants }\end{array}$ & $\begin{array}{c}\text { Reported violence } \\
(\%)\end{array}$ & $\begin{array}{l}\text { Odds ratio (95\% } \\
\text { confidence interval) }\end{array}$ \\
\hline \multicolumn{4}{|l|}{ Age-groups (in years) } \\
\hline $16-29$ & $101(25.2)$ & 32.3 & 1.0 \\
\hline $30-39$ & $110(27.4)$ & 31.3 & $0.9(0.5-1.8)$ \\
\hline $40-49$ & $115(28.7)$ & 43.1 & $1.6(0.9-2.8)$ \\
\hline$\geq 50$ & $75(18.7)$ & 34.3 & $1.1(0.6-2.1)$ \\
\hline \multicolumn{4}{|l|}{ Education status of the participants } \\
\hline Graduate/postgraduate & $73(18.2)$ & 8.7 & 1.0 \\
\hline Secondary/higher secondary & $111(27.7)$ & 15.2 & $1.9(0.7-5.1)$ \\
\hline Primary & $52(13.0)$ & 46.9 & $9.3(3.4-25.5)$ \\
\hline Illiterate & $165(41.1)$ & 57.7 & $14.3(5.9-35.1)$ \\
\hline \multicolumn{4}{|l|}{ Education status of husband } \\
\hline Graduate/postgraduate & $119(29.7)$ & 10.7 & 1.0 \\
\hline Secondary/higher secondary & $114(28.4)$ & 24.1 & $2.6(1.3-5.6)$ \\
\hline Primary & $57(14.2)$ & 55.6 & $10.4(4.7-23.3)$ \\
\hline Illiterate & $111(27.7)$ & 63.8 & $14.5(7.2-30.2)$ \\
\hline \multicolumn{4}{|l|}{ Working status of participants } \\
\hline Housewife & $363(90.5)$ & 35.9 & 1.0 \\
\hline Working outside home & $38(9.5)$ & 33.3 & $0.9(0.4-1.9)$ \\
\hline \multicolumn{4}{|l|}{ Working status of husband } \\
\hline Office worker & $124(30.9)$ & 15.4 & 1.0 \\
\hline Shopkeeper/businessman & $95(23.7)$ & 30.0 & $2.4(1.2-4.6)$ \\
\hline Manual worker/labour & $43(10.7)$ & 40.0 & $3.7(1.6-8.2)$ \\
\hline Retired/jobless & $139(34.7)$ & 56.1 & $7.0(3.9-12.9)$ \\
\hline \multicolumn{4}{|l|}{ Years since marriage } \\
\hline $1-10$ & $116(28.9)$ & 27.3 & 1.0 \\
\hline $11-20$ & $115(28.7)$ & 29.6 & $1.1(0.6-2.0)$ \\
\hline$\geq 21$ & $170(42.4)$ & 45.3 & $2.2(1.3-3.7)$ \\
\hline \multicolumn{4}{|l|}{ Total No. of children } \\
\hline 0 & $34(8.5)$ & 25.0 & 1.0 \\
\hline $1-2$ & $102(25.4)$ & 26.0 & $1.1(0.4-2.7)$ \\
\hline$\geq 3$ & $265(66.1)$ & 40.6 & $2.1(0.9-4.8)$ \\
\hline \multicolumn{4}{|l|}{ Family system } \\
\hline Joint & $149(37.2)$ & 27.7 & 1.0 \\
\hline Nuclear & $252(62.8)$ & 40.3 & $1.8(1.1-2.8)$ \\
\hline \multicolumn{4}{|l|}{ Smoking status of husband } \\
\hline Never smoker & $232(57.9)$ & 24.7 & 1.0 \\
\hline Ex-smoker & $37(9.2)$ & 45.7 & $3.6(1.2-5.4)$ \\
\hline Current smoker & $132(32.9)$ & 52.0 & $3.3(2.2-5.3)$ \\
\hline \multicolumn{4}{|c|}{ Substance use other than tobacco by husband } \\
\hline No & $310(77.3)$ & 29.4 & 1.0 \\
\hline Yes & $91(22.7)$ & 57.0 & $3.2(1.9-5.2)$ \\
\hline
\end{tabular}


in participants whose husbands were addicted to substances other than tobacco $(\mathrm{AOR}=3.1 ; 95 \% \mathrm{CI}$; 1.7-5.7).

Overall, 268 (67\%) participants accepted that a wife should always follow her husband's instructions irrespective of her will and 74 (18.5\%) women agreed that violence against wife was justified if she did not follow her husband's instructions.

The association of women's perspective towards husband's dominance and use of violence against wife with the number of years of school attended by women is shown in the Figure. As the number of years of schooling increased, there was a significant decline in the proportion of women who were in favour of husbands' dominance over wives, and those who accepted violence against wives (Chi squared, $\mathrm{P}<0.001$ ). The Figure depicts that the majority of the illiterate women (over 75\%) agreed that wife should always follow her husband's instructions irrespective of her will, and about 30\% believed that violence against a wife was justified if she did not follow her husband's instructions. On the other hand, less than $5 \%$ of the women who had more than 12 years of education thought that IPV was justified if the husband's instructions were not followed.

\section{Discussion}

Violence against women is being increasingly identified as a major contributor to the ill health and mortality among women. ${ }^{3,10}$ Despite the imperative nature of the problem, there is lack of adequate information on IPV against women in Pakistan. In the current study, we have explored the proportion of women abused by their intimate partners and have identified factors significantly associated with such acts of abuse.

In this study, approximately one third of the women (35\%) reported being ever physically/ verbally violated by their husbands. Other studies from Pakistan ${ }^{15,16}$ have also reported similar findings, with approximately one third to one half of the participants experiencing some form of violence from intimate partners. However, a study conducted in Karachi, Pakistan, among 400 married women showed that the prevalence of IPV (physical violence) was $80 \% .{ }^{17}$ A possible explanation for this high magnitude of IPV prevalence could be the fact that the participants were recruited from low sociodemographic background communities that may be associated with increased perpetuation of violence and vulnerability to the victimisation of violence.

The education status of both the partners has been observed to have significant influence on the prevalence of IPV. ${ }^{19-21}$ Provision of education undoubtedly plays a protective role against IPV. Empowering women through social networking along with income earning improves their capacity
TABLE 2. Multivariate analysis for independent factors associated with intimate partner violence among study participants

\begin{tabular}{|c|c|c|}
\hline Characteristic & $P$ value & $\begin{array}{c}\text { Adjusted odds ratio } \\
\text { (95\% confidence interval)* }\end{array}$ \\
\hline \multicolumn{3}{|l|}{ Education status of participants } \\
\hline Graduate/postgraduate & & 1.0 \\
\hline Secondary/higher secondary & 0.25 & $1.9(0.6-5.8)$ \\
\hline Primary & $<0.001$ & $4.9(1.5-16.3)$ \\
\hline Illiterate & $<0.001$ & $5.9(1.8-19.6)$ \\
\hline \multicolumn{3}{|l|}{ Education status of husband } \\
\hline Graduate/postgraduate & & 1.0 \\
\hline Secondary/higher secondary & 0.37 & $1.5(0.6-3.5)$ \\
\hline Primary & 0.03 & $3.2(1.2-8.7)$ \\
\hline Illiterate & 0.01 & $3.9(1.4-10.7)$ \\
\hline \multicolumn{3}{|l|}{ Smoking status of husband } \\
\hline Never smoker & & 1.0 \\
\hline Ex-smoker & 0.01 & $3.0(1.3-7.1)$ \\
\hline Current smoker & $<0.001$ & $3.3(1.9-5.8)$ \\
\hline \multicolumn{3}{|c|}{$\begin{array}{l}\text { Substance use other than tobacco by } \\
\text { husband }\end{array}$} \\
\hline No & & 1.0 \\
\hline Yes & $<0.001$ & $3.1(1.7-5.7)$ \\
\hline
\end{tabular}

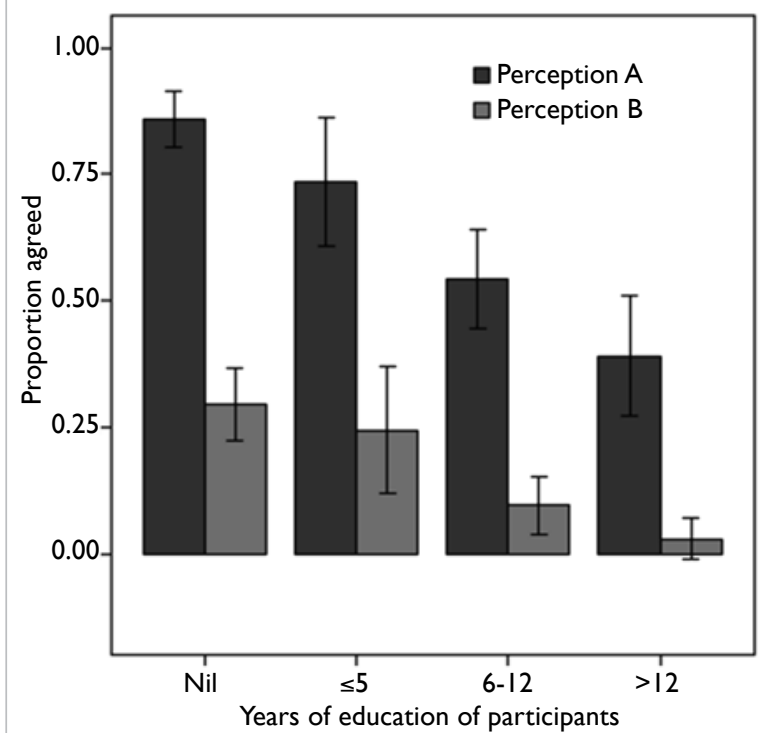

FIG. Association of education status with women's attitude towards intimate partner violence

Perception A: Wife should always follow her husband's

instructions irrespective of her will

Perception B: Violence against wife is justified if she does not follow her husband's instructions

Error bars denote standard deviations 
to access information and resources available in society, and seek help in case of spousal abuse. ${ }^{19}$ The results of the current study also clearly indicate a positive association between the literacy levels of husband and wife and IPV victimisation among women. Education also imparts a protective role through influencing the perspectives of individuals, and societies in general, against the acceptability of mistreatment towards women. ${ }^{19}$ A climate of tolerance towards IPV makes it easier for perpetrators to persist with their violent behaviour. ${ }^{22}$ Education inculcates a sense of self-respect and selfreliance in women, enhancing their capacity to make appropriate decisions regarding various aspects of their lives confidently and autonomously. ${ }^{11}$ On the other hand, lack of education not only deprives women from acknowledging their rights but, instead, stigmatises their thinking on gender roles and makes them more accepting towards use of force to impose these roles. ${ }^{23,24}$ This effect was observed in previous studies in which low level of education was associated with women's acceptance of wife battering, whereas higher education level was negatively associated with tolerance of wife beating. Furthermore, educated women were most protected against violence. ${ }^{23,24}$ This is also reflected in the findings of this study in that acceptance and tolerance towards husband's mistreatment and control over the wife markedly declined as the education level of the women improved.

The results of the current study also indicate that women whose husbands smoke or consume other substances of abuse experience increased levels of IPV. This is consistent with the findings of previous studies $^{20,25,26}$ which showed that smoking, alcohol consumption, and using other substances of abuse were strongly associated with IPV. Substance abuse, including smoking and alcohol consumption, may be directly responsible for IPV by affecting cognition, reducing self-control, perpetuating aggression and may also induce stress and unhappiness in relationships, thereby, further increasing the risk of violence and conflict. ${ }^{26}$

This study has some limitations. It was conducted in selective family practice clinics which may have underestimated the results due to underreporting. Since these clinics are situated in urban areas of a single city, the participants may not represent the population at large. Moreover, the response rate was low in this study $(77 \%)$ due to the sensitive nature of the issue. There is also a chance of selection bias. As this was a cross-sectional study, temporality or causality could not be established. Owing to the cultural and social restrictions, we did not enquire about sexual abuse. Moreover, due to sensitivity of the issue, there may have been underreporting of such information. We had asked about the abuse ever in the lifetime; therefore, there is some possibility of recall bias as well. Hence, the actual burden of the problem may be higher than what we have reported. Finally, the questionnaire used in this study is not a validated tool, so there is a chance of information bias in the study.

\section{Conclusion}

In the light of the above findings, it is imperative that VAW be considered a major public health concern. The prevention of VAW can be achieved through comprehensive, multifaceted, and integrated approaches that require joint efforts by the government, policy-makers, social workers, religious scholars, educationalists, and public health practitioners. In this respect, the role of education is greatly emphasised in changing the perspectives of individuals and societies against IPV. Family physicians, being the first-line doctors and health care providers, should be well trained in screening for IPV and providing instantaneous care to the victims by catering to their psychological needs to prevent poor mental health outcomes.

\section{References}

1. Hogan MC, Foreman KJ, Naghavi M, et al. Maternal mortality for 181 countries, 1980-2008: a systematic analysis of progress towards Millennium Development Goal 5. Lancet 2010;375:1609-23.

2. Heise L. Violence against women: the hidden health burden. World Health Stat Q 1993;46:78-85.

3. Carolissen R. World report on violence and health. S Afr Med J 2003;93:272.

4. Sarkar NN. The impact of intimate partner violence on women's reproductive health and pregnancy outcome. J Obstet Gynecol 2008;28:266-71.

5. Bailey BA, Daugherty RA. Intimate partner violence during pregnancy: incidence and associated health behaviors in a rural population. Matern Child Health J 2007;11:495-503.

6. Ruiz-Pérez I, Plazaola-Castaño J, Del Río-Lozano M. Physical health consequences of intimate partner violence in Spanish women. Eur J Public Health 2007;17:437-43.

7. Abrahams N, Jewkes R, Martin LJ, Mathews S, Vetten L, Lombard C. Mortality of women from intimate partner violence in South Africa: a national epidemiological study. Violence Vict 2009;24:546-56.

8. Bair-Merritt MH, Blackstone M, Feudtner C. Physical health outcomes of childhood exposure to intimate partner violence: a systematic review. Pediatrics 2006;117:e278-90.

9. Graham-Bermann SA, Gruber G, Howell KH, Girz L. Factors discriminating among profiles of resilience and psychopathology in children exposed to intimate partner violence (IPV). Child Abuse Negl 2009;33:648-60.

10. Garcia-Moreno C, Jansen HA, Ellsberg M, et al. Prevalence of intimate partner violence: findings from the WHO multi-country study on women's health and domestic violence. Lancet 2006;368:1260-9.

11. Abramsky T, Watts CH, Garcia-Moreno C, et al. What factors are associated with recent intimate partner violence? Findings from the WHO multi-country study on women's health and domestic violence. BMC Public Health 
2011;11:109.

12. Ahmad F, Hogg-Johnson S, Stewart DE, Levinson W. Violence involving intimate partners: prevalence in Canadian family practice. Can Fam Physician 2007;53:4608.

13. Chandra PS, Satyanarayana VA, Carey MP. Women reporting intimate partner violence in India: associations with PTSD and depressive symptoms. Arch Womens Ment Health 2009;12:203-9.

14. Silverman JG, Decker MR, Gupta J, Kapur N, Raj A, Naved RT. Maternal experiences of intimate partner violence and child morbidity in Bangladesh: evidence from a national Bangladeshi sample. Arch Pediatr Adolesc Med 2009;163:700-5.

15. Andersson N, Cockcroft A, Ansari U, et al. Barriers to disclosing and reporting violence among women in Pakistan: findings from a national household survey and focus group discussions. J Interpers Violence 2010;25:196585.

16. Farid M, Saleem S, Karim MS, Hatcher J. Spousal abuse during pregnancy in Karachi, Pakistan. Int J Gynaecol Obstet 2008;101:141-5.

17. Ali TS, Bustamante-Gavino I. Prevalence of and reasons for domestic violence among women from low socioeconomic communities of Karachi. East Mediterr Health J 2007;13:1417-26.

18. Shaikh MA. Domestic violence against women-perspective from Pakistan. J Pak Med Assoc 2000;50:312-4.

19. Boyle MH, Georgiades K, Cullen J, Racine Y. Community influences on intimate partner violence in India: women's education, attitudes towards mistreatment and standards of living. Soc Sci Med 2008;69:691-7.

20. Ntaganira J, Muula AS, Siziya S, Stoskopf C, Rudatsikira E. Factors associated with intimate partner violence among pregnant rural women in Rwanda. Rural Remote Health 2009;9:1153.

21. Vives-Cases C, Alvarez-Dardet C, Gil-González D, Torrubiano-Domínguez J, Rohlfs I, Escribà-Agüir V. Sociodemographic profile of women affected by intimate partner violence in Spain [in Spanish]. Gac Sanit 2009;23:410-4.

22. Seth P, Raiford JL, Robinson LS, Wingood GM, DiClemente RJ. Intimate partner violence and other partner-related factors: correlates of sexually transmissible infections and risky sexual behaviours among young adult African American women. Sexual Health 2010;7:25-30.

23. Rani M, Bonu S. Attitudes toward wife beating a crosscountry study in Asia. J Interpers Violence 2009;24:137197.

24. Dhaher EA, Mikolajczyk RT, Maxwell AE, Kramer A. Attitudes toward wife beating among Palestinian women of reproductive age from three cities in West Bank. J Interpers Violence 2010;25:518-37.

25. Easton CJ, Weinberger AH, McKee SA. Cigarette smoking and intimate partner violence among men referred to substance abuse treatment. Am J Drug Alcohol Abuse 2008;34:39-46.

26. Stuart GL, Temple JR, Follansbee KW, Bucossi MM, Hellmuth JC, Moore TM. The role of drug use in a conceptual model of intimate partner violence in men and women arrested for domestic violence. Psychol Addict Behav 2008;22:12-24. 